\title{
CLL and COVID-19 at the Hospital Clinic of Barcelona: an interim report
}

\author{
Tycho Baumann $^{1} \cdot$ Julio Delgado $^{1} \cdot$ Emili Montserrat $^{1}$
}

Received: 15 April 2020 / Revised: 24 April 2020 / Accepted: 11 May 2020 / Published online: 19 May 2020

(c) Springer Nature Limited 2020

\section{To the Editor:}

COVID-19 caused by SARS-CoV-2 has lead to a global pandemic already affecting over 3.5 million persons with more than 243,000 confirmed deaths [1]. Early reports from China indicate that persons with cancer are more susceptible to SARS-CoV-2 [2]. However, there are no data on the prevalence of COVID-19 in different types of cancer, including chronic lymphocytic leukemia (CLL).

CLL is the most frequent leukemia in Western countries with an incidence of 4.2:100,000/year, increasing to more than 30:100,000/year at an age of $>80$ years. The median age at diagnosis is 72 years, and most patients are older than 60 years. Data from US SEER estimated >20,000 newly diagnosed cases of CLL in 2019 [3]. CLL is frequently accompanied by immunodefiency (that can be aggravated by therapy) and comorbidity. Infections are the first cause of death in CLL. Cancer, older age, inmmunodeficiency, and chronic diseases are all risk factors for COVID-19 [4]. It could be hypothesized, therefore, that patients with CLL are among those with a higher risk to contract COVID-19. However, the prevalence, clinical characteristics, and outcome of patients with CLL and COVID-19 infection have not yet been established, and to obtain the full picture will take time. Meanwhile, preliminary information from large series of patients can be useful.

The Hospital Clinic from Barcelona is a reference center for CLL. In the period 2000-2019, 804 patients with CLL were registered. The median age was 67 years. The median overall survival is 11.8 years. Three hundred and eightyfour patients have died; in 236 with available information, infection was the cause of death in $35 \%$ subjects. The

Emili Montserrat

emontse@clinic.cat

1 Department of Hematology, Hospital Clinic University of Barcelona, Barcelona, Spain median follow-up of 420 patients who remain alive is 7.9 years. Four of these patients $(0.95 \%)$ have been diagnosed with symptomatic COVID-19. Their characteristics and outcome are shown in the Table 1. Of note, the number of patients with COVID-19 admitted at the Hospital Clinic of Barcelona as of 6 May 2020 is 2366.

All four patients were males, old and suffered from comorbidity; three had increased ferritin levels; two presented lymphocytopenia; and one had increased D-dimer levels, all features associated with poor outcome in COVID19 [4]. Also, two patients had previously received therapy for CLL. Despite this, the course of the disease was mild, and no patient required admission in an intensive care unit; three patients quickly recovered after 4-8 days and one after 24 days of experimental therapy for COVID-19. It could be speculated that the CLL-related immunodeficiency, rather than exacerbating the effects of SARS-Cov-2 might prevent them [5]. This, as well as the potential role of immunomodulatory agents (e.g., ibrutinib) on the outcome of patients with CLL infected by SARS-Cov-2, deserves investigation $[6,7]$.

The concept that patients with cancer have a high-risk for COVID-19 derives from reports describing the underlying conditions in patients with COVID-19 [8, 9]. Ours is the first attempt to directly determining the prevalence of COVID-19 in CLL. In short, 4 of 420 (0.95\%) patients, representative of the general CLL population, have been so far diagnosed with mild, symptomatic COVID-19. The seemingly low prevalence of symptomatic COVID-19 in CLL needs to be taken cautiously as the number of cases may increase as long as the pandemic persists. Several recently launched studies, will help to clarify the prevalence of COVID-19 in CLL, its clinical characteristics, optimal therapy, and outcome. Meanwhile, this interim report based on a large series of patients provides a frame to gauge the likely impact of COVID-19 on patients with CLL. Also, different organisms have issued helpful recommendations on the prevention of COVID-19 in patients with CLL or cancer in this dramatic and challenging moment $[10,11]$. 


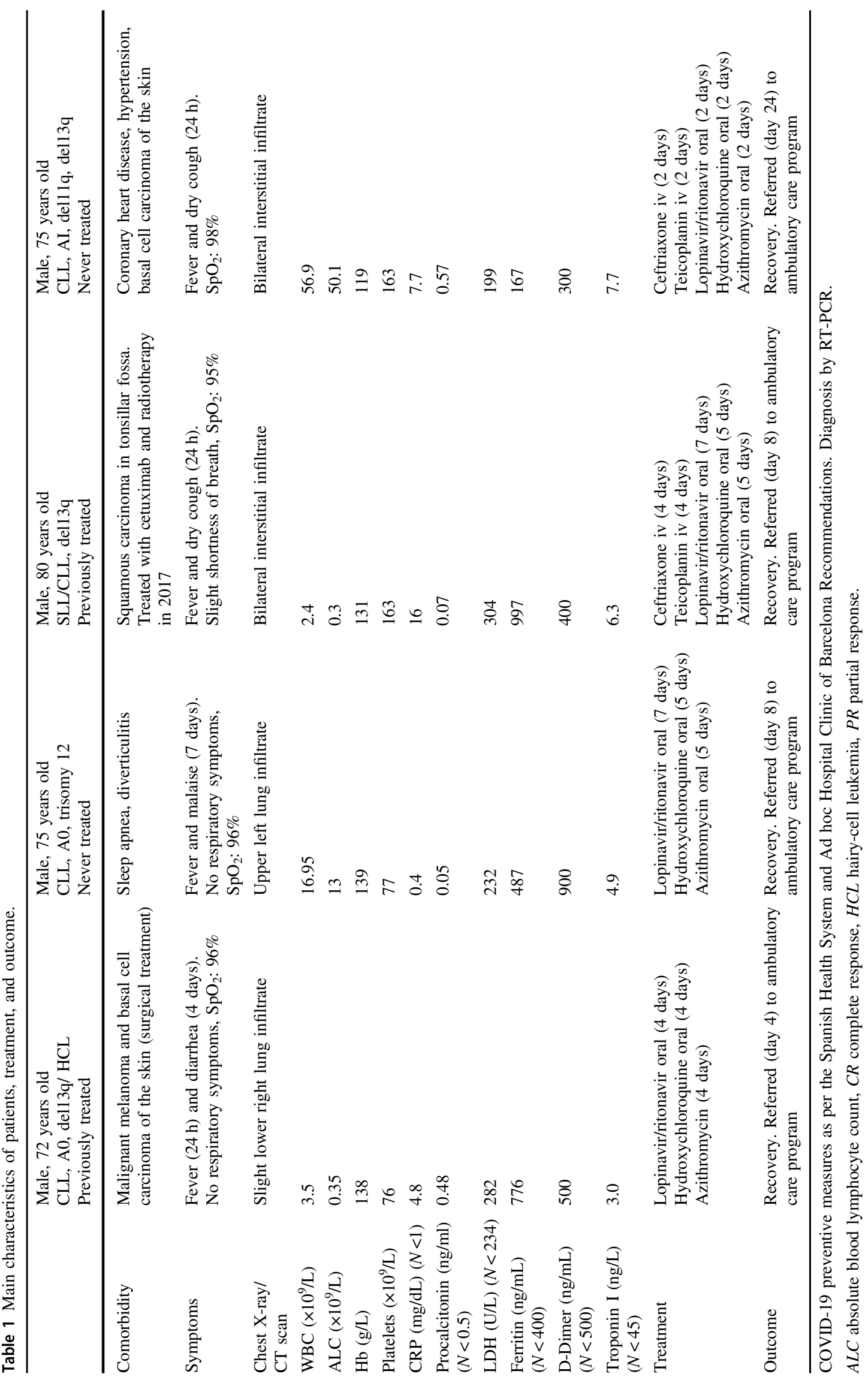


Acknowledgements Thanks are due to Antoni Trilla (Department of Epidemiology, Hospital Clínic Barcelona) and Antoni Castells (Medical Director, Hospital Cínic Barcelona) for helpful information, and to all membres from the COVID-19 Team from the Hospital Clinic Barcelona, patients, and relatives for their exemplary courage.

\section{Compliance with ethical standards}

Conflict of interest The authors declare that they have no conflict of interest.

Publisher's note Springer Nature remains neutral with regard to jurisdictional claims in published maps and institutional affiliations.

\section{References}

1. https://www.who.int/emergencies/diseases/novel-coronavirus2019. Accessed 5 May 2020.

2. Liang W, Guan W, Chen R, Wang W, Li J, Xu K, et al. Cancer patients in SARS-CoV-2 infection: a nationwide analysis in China. Lancet Oncol. 2020;21:335-7.

3. https://seer.cancer.gov/statfacts/html/clyl.html. Accessed 5 May 2020.

4. Zhou F, Yu T, Du R, Fan G, Liu Y, Liu Z, et al. Clinical course and risk factors for mortality of adult inpatients with COVID-19 in
Wuhan, China: a retrospective cohort study. Lancet Oncol. 2020;395:1054-62.

5. Ziegler CGK, Allon SJ, Nyquist SK, Mbano IM, Miao VM, Tzouanas CN, et al. SARS-CoV-2 receptor ACE2 is an interferonstimulated gene in human airway epithelial cells and is detected in specific cell subsets across tissues. Cell. 2020. https://doi.org/10. 1016/j.cell.2020.04.035.

6. Weber ANR, Bittner Z, Liu X, Dang T-M, Radstac, Ph, Brunner CI. Bruton's tyrosine kinase: an emerging key player in innate immunity. Front Immunol. 2017;8:1454.

7. Treon S, Castillo J, Skarbnik A, Soumerai J, Ghobrial I, Guerra ML, et al. The BTK-inhibitor ibrutinib may protect against pulmonary injury in COVID-19 infected patients. Blood 2020. https://doi.org/10.1182/blood.2020006288.

8. Emani A, Javanmardi F, Pirbonyeh N, Akbari A. Prevalence of underlying diseases in hospitalized patients with COVID-19: a systematic review and meta-analysis. Arch Academic Emerg Med. 2020;8:e35.

9. CDC COVID-19 Response Team. MMWR 2020;69:382-286.

10. ASH recommendations (endorsed by ERIC/EHA). 2020. https:// www.hematology.org/covid-19/covid-19-and-cll.

11. von Lilienfeld-Toal M, Vehreschild JJ, Cornely O, Pagano L, Compagno F, EHA Infectious Disease Scientific Working Group, et al. Frequently asked questions regarding SARS-CoV2 in cancer patients-recommendations for clinicians caring for patients with malignant diseases. Leukemia. (in press). 